\title{
Erratum: Buffeting reliability of bridges with structural uncertainties
}

\section{Cheng Su PhD}

Professor, School of Civil Engineering and Transportation, State Key Laboratory of Subtropical Building Science, South China University of

Technology, Guangzhou, China

Xiaofeng Chen MEng

Engineer, Architectural Design and Research Institute, South China

University of Technology, Guangzhou, China

\section{Junjie Luo PhD}

Associate Professor, Earthquake Engineering Research and Test Center, Guangzhou University, State Key Laboratory of Subtropical Building Science, South China University of Technology, Guangzhou, China
The publisher regrets that the following errors appeared in this paper when it was published in Bridge Engineering 168(1): 30-42.
Number of random variables was given the notation $n_{i}\left(f_{x_{1}}, x_{2}, \ldots, x_{n}\left(x_{1}, x_{2}, \ldots\right.\right.$, $\left.x_{n}\right)$ ) in the notation list. It should have had the notation $n$. Time was given the notation $t_{i}\left(x_{1}, x_{2}, \ldots, x_{n}\right)$. It should have had the notation $t$. 